\title{
Atividade do sistema antioxidante e desenvolvimento de aerênquima em raízes de milho 'Saracura'
}

\author{
Fabricio José Pereira(1), Paulo César Magalhães ${ }^{(2)}$, Thiago Corrêa de Souza(1), \\ Evaristo Mauro de Castro(1) e José Donizeti Alves ${ }^{(1)}$
}

\begin{abstract}
(1)Universidade Federal de Lavras, Departamento de Biologia, Setor de Fisiologia Vegetal, Caixa Postal 37, Campus Universitário, CEP 37200-000 Lavras, MG. E-mail: fjprock@hotmail.com, thiagonepre@hotmail.com, emcastro@ufla.br, jdalves@ufla.br (2)Embrapa Milho e Sorgo, Caixa Postal 151, CEP 37701-970 Sete Lagoas, MG. E-mail: pcesar@cnpms.embrapa.br
\end{abstract}

Resumo - Este trabalho teve como objetivo avaliar a influência de sucessivos ciclos de seleção do milho 'Saracura' na atividade das enzimas do sistema antioxidante, e a relação dessas enzimas com a capacidade dessa variedade em desenvolver aerênquima. Sementes de 18 ciclos de seleção intercalados do milho 'Saracura' e da cultivar BR 107, sensível à hipoxia, foram semeadas em vasos e em casa de vegetação. As plantas foram submetidas ao alagamento intermitente de dois em dois dias. As amostras de raízes foram coletadas após 60 dias e analisaram-se as atividades das enzimas peroxidase do guaiacol, peroxidase do ascorbato e catalase, além da capacidade das plantas de cada ciclo desenvolverem aerênquima. Ao longo dos ciclos, as plantas apresentaram modificações na atividade das enzimas, com aumento na de peroxidase do ascorbato e diminuição na de catalase e de peroxidase do guaiacol. Observou-se, ainda, maior capacidade de desenvolver aerênquima nos últimos ciclos de seleção. A redução na atividade das enzimas do sistema antioxidante parece estar relacionada a um desbalanço na decomposição de $\mathrm{H}_{2} \mathrm{O}_{2}$.

Termos para indexação: Zea mays, catalase, peroxidases, seleção massal, tolerância ao alagamento.

\section{Antioxidant system activity and aerenchyma formation in 'Saracura' maize roots}

\begin{abstract}
This work aimed to assess the influence of successive selection cycles in 'Saracura' maize on the enzyme activity of the antioxidant system and the relationship of these enzymes with the aerenchyma development capacity of this variety. Seeds of 18 intercalated selection cycles of the 'Saracura' maize and of the cultivar BR 107, sensitive to hipoxia, were sown in pots in the greenhouse. Plants were submitted to intermittent soil flooding each two days. After 60 days, the roots were sampled and analysis were done for the guaiacol peroxidase, ascorbate peroxidase, and catalase activities and for the capacity of the plants of each cycle to develop aerenchyma. The plants showed modifications in enzyme activity along the cycles, increasing the ascorbate peroxidase activity and decreasing the catalase and guaiacol peroxidase ones. A greater capacity to develop aerenchyma was also observed in the last selection cycles. Reductions in the enzyme activity of the antioxidant system seem to be related to a disorder in the $\mathrm{H}_{2} \mathrm{O}_{2}$ decomposition capacity.
\end{abstract}

Index terms: Zea mays, catalase, peroxidases, massal selection, tolerance to flooding.

\section{Introdução}

No Brasil, existem aproximadamente 28 milhões de hectares com potencial agrícola que estão sob regime de inundação intermitente (Andrade et al., 1999). Nessas condições, a água ocupa os espaços que seriam preenchidos pelo ar, o que gera uma situação de hipoxia, caracterizada pela deficiência de $\mathrm{O}_{2}$ (Kozlowski, 1984, 1997), com reflexos substanciais sobre a produção das plantas.

O insucesso do desenvolvimento da cultura do milho em solos com excesso de água está relacionado à alta sensibilidade dessa cultura à hipoxia. Nesse contexto, a Embrapa Milho e Sorgo lançou, em 1997, a variedade de milho Saracura (BRS-4154), tolerante ao alagamento. Após vários ciclos de seleção massal sob condições de alta umidade do solo, essa variedade revelou-se uma das mais adequadas para o cultivo em áreas sujeitas ao encharcamento (Alves et al., 2002). Apesar de o solo com deficiência de oxigênio apresentar condições desfavoráveis à vida das plantas, o milho 'Saracura' desenvolveu mecanismos para sobreviver e produzir sob essas condições. Entre as alterações que

Pesq. agropec. bras., Brasília, v.45, n.5, p.450-456, maio 2010 
permitem a essa variedade tolerar baixa concentração de oxigênio no ambiente radicular, encontram-se as de natureza metabólica e molecular, que incluem o desvio da respiração aeróbica para a via anaeróbica (Alves et al., 2002).

Nos últimos anos, tem-se dado especial atenção aos danos celulares oxidativos nas raízes causados pelo acúmulo de espécies reativas de oxigênio (EROs), sob condições em que a fosforilação oxidativa é reduzida em razão da deficiência de $\mathrm{O}_{2}$. Em plantas, está bem caracterizado que, sob condições de hipoxia no solo, ocorre um aumento descontrolado de radicais livres nas células (Blokhina et al., 2003). Modificações na estrutura e nas funções das membranas, resultantes da peroxidação de seus lipídeos, são também bem caracterizadas (Cakmak \& Horst, 1991), e podem resultar em danos ao funcionamento e à estrutura celular (Mittler et al., 2004). A morte celular programada, também chamada de apoptose, é um processo diretamente relacionado ao aumento nas espécies reativas de oxigênio, que sinalizam para a morte celular (Krishnamurthy et al., 2000). Em Arabidopsis, a sinalização para o desenvolvimento de aerênquimas nas raízes está diretamente relacionada à produção de $\mathrm{H}_{2} \mathrm{O}_{2}$ e de etileno, e também com a inibição da peroxidase do ascorbato (Mühlenbock et al., 2007).

As enzimas do sistema antioxidante são ainda pouco estudadas sob condições de alagamento (Sairam et al., 2008). Em folhas de milho, o alagamento prolongado promoveu redução na atividade das enzimas redutase da glutationa, peroxidase do ascorbato, catalases e superóxido dismutase, enquanto um alagamento em período curto estimulou a atividade dessas enzimas (Yan et al., 1996). As enzimas catalase, peroxidase do ascorbato e peroxidase do guaiacol são especializadas na remoção de $\mathrm{H}_{2} \mathrm{O}_{2}$ (Moller et al., 2007). Este oxidante é relativamente estável e, pela ausência de cargas, tem sua passagem facilitada pela bicamada lipídica da membrana celular, o que sinaliza para a apoptose e, consequentemente, influencia na formação de aerênquima do tipo lisígino (Krishnamurthy et al., 2000; Mühlenbock et al., 2007; Sairam et al., 2008). Além disso, a síntese dessa molécula é expressivamente ativada pelo alagamento (Moller et al., 2007), que também pode ser relacionado à diminuição da atividade de peroxidases e catalase (Yan et al., 1996).

Em termos morfológicos, uma das principais adaptações ao encharcamento é a formação de aerênquima nas raízes, que se inicia na região central do córtex para, posteriormente, se espalhar de forma radial e tangencial (Bouranis et al., 2006). $\mathrm{O}$ desenvolvimento do aerênquima leva à formação de espaços intercelulares que facilitam a difusão de gases (Gunawardena, 2008) e, consequentemente, permitem melhor distribuição do $\mathrm{O}_{2}$ nos tecidos das plantas. $\mathrm{O}$ aerênquima pode estar presente em folhas, pecíolos, caules e raízes, podendo surgir por separação das células, processo denominado esquizogenia, e por lise de células, ou lisigenia (Schussler \& Longstreth, 1996), de maneira constitutiva ou em resposta a um estímulo ambiental.

Em plantas de milho 'Saracura', a hipoxia induz o desenvolvimento de aerênquima predominantemente lisígeno, e a capacidade em desenvolver aerênquima nessa variedade aumenta nos últimos ciclos de seleção (Pereira et al., 2008; Souza et al., 2009). Essa variedade apresenta, ainda, plasticidade foliar para a adaptação a ambientes alagados (Souza et al., 2010).

Este trabalho teve como objetivo avaliar a influência dos sucessivos ciclos de seleção do milho 'Saracura' na atividade das enzimas do sistema antioxidante, e a relação dessas enzimas com a capacidade dessa variedade em desenvolver aerênquima.

\section{Material e Métodos}

Os ciclos de seleção genética (C) do milho 'Saracura' foram realizados em plantios anuais sob condições de alagamento intermitente, e as plantas que apresentaram o melhor desempenho foram selecionadas para o replantio no ano seguinte. Sementes de milho Saracura BRS-4154 colhidas em lavouras dos ciclos de seleção (C) 1, 3, 5, 7, 9, 11, 13, 15, 17 e 18, e da cultivar BR 107, classificada como sensível ao alagamento (Alves et al., 2002), foram semeadas em vasos contendo $20 \mathrm{~L}$ de solo de várzea, classificado como Planosolo Hidromórfico eutrófico arênico. Cada vaso recebeu a seguinte adubação em cobertura: $0,075 \mathrm{~g} \mathrm{~kg}^{-1}$ de sulfato de amônia, em duas aplicações semanais; $0,0333 \mathrm{~g} \mathrm{~kg}^{-1}$ de ureia, em quatro aplicações semanais; $0,3 \mathrm{~g} \mathrm{~kg}^{-1}$ de $\mathrm{Zn}$; e $1 \mathrm{~mL} \mathrm{~kg}^{-1}$ de deltametrina (Ferrer et al., 2005), em três doses semanais. Quinze dias após a semeadura, procedeu-se ao desbaste das plântulas, tendo-se deixado duas por vaso.

Até o estádio V6, em que as plantas se encontram com seis folhas completamente desenvolvidas, o 
conteúdo de água no solo foi mantido próximo à capacidade de campo. A partir daí, iniciou-se o tratamento de encharcamento intermitente do solo com adição de água em excesso, até a altura de $1,0 \mathrm{~cm}$ acima do nível de solo, a cada dois dias. No intervalo, não se adicionou água, deixando-a drenar livremente até a próxima adição. $\mathrm{O}$ delineamento experimental foi o inteiramente ao acaso, com um vaso por parcela e quatro repetições.

Sessenta dias após o primeiro encharcamento, foram coletadas amostras de raízes para a análise das atividades enzimáticas e da proporção do córtex radicular ocupada pelo aerênquima. A parte aérea foi excisada e o sistema radicular foi cuidadosamente lavado com água corrente, até a completa remoção do solo. Em seguida, amostras de $5 \mathrm{~g}$ de raízes foram separadas, envolvidas em papel-alumínio e mergulhadas em nitrogênio líquido e transferidas para freezer a $-86^{\circ} \mathrm{C}$, até o momento das análises enzimáticas.

Foram maceradas $0,3 \mathrm{~g}$ de raízes em nitrogênio líquido. Em seguida, foi adicionado $0,9 \mathrm{~mL}$ de um tampão de extração adaptado de Bor et al. (2003), constituído de $883,8 \mu \mathrm{L}$ de tampão fosfato $0,1 \mathrm{M} \mathrm{pH} 7$, $9 \mu \mathrm{L}$ de EDTA $0,1 \mathrm{M}, 3,6 \mu \mathrm{L}$ de DTT $0,5 \mathrm{M}, 7,2 \mu \mathrm{L}$ de PMSF 0,1M e 18 mg de PVPP. Após homogeneização, o extrato enzimático foi centrifugado a $14.000 \mathrm{~g}$, por 20 minutos, a $4^{\circ} \mathrm{C}$, e coletado o sobrenadante, onde foram realizadas as determinações das atividades das enzimas peroxidase do guaiacol (POD), peroxidase do ascorbato (APX) e catalase (CAT).

A atividade de POD foi analisada com a adição de

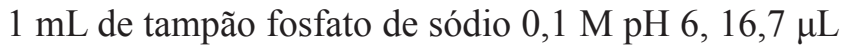
de guaiacol 0,2 M, 13,3 $\mu \mathrm{L}$ de $\mathrm{H}_{2} \mathrm{O}_{2} 0,03 \mathrm{M}$, em $20 \mu \mathrm{L}$ do extrato enzimático adaptado de Nakano \& Asada (1981). A atividade enzimática foi determinada pelo acompanhamento do aumento da absorbância a $470 \mathrm{~nm}$ por $2 \mathrm{~min}$, em intervalos de 15 segundos, e calculada com base no fator de extinção de $26,6 \mathrm{mM}^{-1} \mathrm{~cm}^{-1}$.

A APX foi analisada com a adição de $0,9 \mathrm{~mL}$ de

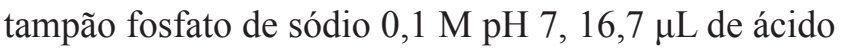
ascórbico $0,01 \mathrm{M}, 13,3 \mu \mathrm{L}$ de $\mathrm{H}_{2} \mathrm{O}_{2}$ 0,03 M em $20 \mu \mathrm{L}$ do extrato enzimático adaptado de Nakano \& Asada (1981). A atividade enzimática foi determinada pelo acompanhamento da queda da absorbância, a $290 \mathrm{~nm}$, por 2 minutos, em intervalos de 15 segundos, e calculada com base no fator de extinção de $2,8 \mathrm{mM}^{-1} \mathrm{~cm}^{-1}$.

Para quantificar a atividade de CAT, adicionouse, em $20 \mu \mathrm{L}$ do extrato enzimático, $0,98 \mathrm{~mL}$ de tampão fosfato de sódio $0,05 \mathrm{M} \mathrm{pH} \mathrm{7,} \mathrm{H}_{2} \mathrm{O}_{2} 0,0125 \mathrm{M}$ dissolvido no tampão adaptado de Madhusudhan et al. (2003). A atividade enzimática foi determinada pelo acompanhamento da queda da absorbância a $240 \mathrm{~nm}$, por 2 minutos, em intervalos de 15 segundos, e calculada com base no fator de extinção de $36 \mathrm{mM}^{-1} \mathrm{~cm}^{-1}$.

Nas análises de aerênquima, foram coletadas aleatoriamente em cada planta, cinco raízes contendo as regiões apical, de alongamento, pilífera e basal. Após sucessivas lavagens, as raízes foram fixadas em solução de formaldeído, ácido acético e etanol a 70\% (FAA 70) (Johansen, 1940), por 48 horas e, em seguida, preservadas em etanol a $70 \%$, até a data das análises (Grisi et al., 2008). Fragmentos de raízes cortados a $4 \pm 0,5 \mathrm{~cm}$ a partir do ápice radicular (Melo et al., 2007) foram utilizados para a realização de cortes transversais em micrótomo de mesa. Os cortes foram clarificados com hipoclorito de sódio a 5\%, por $10 \mathrm{~min}$, reidratados por $10 \mathrm{~min}$, corados com astrablau, que consiste em uma solução de safranina e azul de astra 7,5:2,5, e montados em lâminas com glicerina a 50\% (Kraus \& Arduin, 1997). Foi utilizado microscópio óptico acoplado a uma câmera digital, com a qual foram realizadas fotografias dos cortes. Estas foram utilizadas para as medições dos parâmetros anatômicos, pelo programa de análise de imagem Imagetool (University of Texas Health Science Center, 2002), calibrado com régua microscópica fotografada nos mesmos aumentos das fotografias.

Foram realizadas quatro medições de cada característica anatômica, em cada repetição, para a determinação das médias. A proporção da área ocupada pelo aerênquima no córtex foi calculada com base na divisão da área total de aerênquima formado pela área total do córtex. Utilizaram-se a análise de variância e o teste de Scott-Knott, a 5\% de probabilidade, para a análise estatística dos resultados.

\section{Resultados e Discussão}

Do ciclo de seleção 1 (C1) para o ciclo 18 (C18) observou-se aumento significativo na área de aerênquima, de 0,27 para $2,03 \mathrm{~mm}^{2}$, que ocuparam proporcionalmente $8,7 \%$ e $49,01 \%$ da região do córtex, respectivamente (Tabela 1 e Figura 1). No caso da cultivar BR 107, a área de aerênquima foi de $0,07 \mathrm{~mm}^{2}$, que representa $1,46 \%$ da área do córtex. A proporção de aerênquima no córtex no milho 'Saracura' em relação 
à 'BR 107 ' foi maior em todos os ciclos de seleção. Nos ciclos iniciais (C1 a C3), observa-se menor proporção de aerênquima em relação aos intermediários (C5 a C13), sendo que as maiores proporções foram observadas nos ciclos finais (C15 a C18).

Em relação à CAT, de maneira geral, verificou-se diminuição em sua atividade radicular nos ciclos finais de seleção, quando comparada à dos ciclos iniciais, que exibiram valores próximos aos observados na 'BR 107' (Figura 2). Essa enzima está presente nos peroxissomos e age decompondo o $\mathrm{H}_{2} \mathrm{O}_{2}$ em oxigênio molecular e água (Moller et al., 2007).

Alternativamente, $\mathrm{o} \mathrm{H}_{2} \mathrm{O}_{2}$ pode ser removido das células pela POD. Essa enzima apresentou maior atividade nos ciclos intermediários ( $\mathrm{C} 5$ a $\mathrm{C} 11)$, com redução nos ciclos subsequentes, tendo exibido nos ciclos finais $\mathrm{C} 17 \mathrm{e} \mathrm{C} 18$ atividades inferiores à observada em 'BR 107' (Figura 2).

Tabela 1. Área de total de aerênquima no córtex (AAE) e proporção dessa área em relação à área total do córtex (PA) em raízes de milho 'Saracura' e da cultivar BR $107^{(1)}$.

\begin{tabular}{lcc}
\hline Ciclos & AAE $\left(\mathrm{mm}^{2}\right)$ & PA $(\%)$ \\
\hline BR 107 & $0,07 \mathrm{c}$ & $01,46 \mathrm{~d}$ \\
C1 & $0,27 \mathrm{c}$ & $08,70 \mathrm{c}$ \\
C3 & $0,25 \mathrm{c}$ & $09,15 \mathrm{c}$ \\
C5 & $0,49 \mathrm{c}$ & $29,14 \mathrm{~b}$ \\
C7 & $0,69 \mathrm{~b}$ & $30,34 \mathrm{~b}$ \\
C9 11 & $0,92 \mathrm{~b}$ & $35,87 \mathrm{~b}$ \\
C11 13 & $1,27 \mathrm{a}$ & $34,99 \mathrm{~b}$ \\
C15 & $1,03 \mathrm{a}$ & $38,98 \mathrm{~b}$ \\
C17 18 & $1,38 \mathrm{a}$ & $40,56 \mathrm{a}$ \\
C18 & $1,19 \mathrm{a}$ & $45,16 \mathrm{a}$ \\
\hline
\end{tabular}

${ }^{(1)}$ Médias seguidas por letras iguais não diferem entre si pelo teste de SkottKnott a 5\% de probabilidade.
A APX, que também pode degradar o $\mathrm{H}_{2} \mathrm{O}_{2}$, teve sua atividade aumentada entre o $\mathrm{C} 1$ e $\mathrm{C} 18$, ao contrário do observado em CAT e POD (Figura 2). Essa enzima utiliza o ascorbato como doador específico de elétrons para reduzir o $\mathrm{H}_{2} \mathrm{O}_{2}$ à água, o que gera monodehidroascorbato que, por sua vez, é regenerado novamente a ascorbato para que o sistema antioxidante se mantenha ativo.

No processo de seleção, houve estímulo para a formação de aerênquima no córtex da raiz (Figura 1). Essas estruturas permitem a oxigenação interna dos tecidos radiculares (Bouranis et al., 2006), o que é fundamental para manter o metabolismo aeróbico na raiz, ainda que em ambientes hipóxicos ou anóxicos (Insausti et al., 2001; Gunawardena, 2008). Portanto, essa estratégia permite ao milho 'Saracura' crescer e sobreviver por períodos de tempo maiores que outras cultivares que não apresentam tais estruturas. $\mathrm{O}$ aumento na proporção de aerênquima no córtex radicular do milho 'Saracura' está de acordo com o observado por Pereira et al. (2008) e Souza et al. (2009).

Trabalhos anteriores (Alves et al., 2002; Pereira et al., 2008; Souza et al., 2009, 2010) relataram superioridade do milho 'Saracura' em relação à cultivar BR 107, no que se refere à tolerância ao alagamento, o que é condizente com o aumento na proporção do córtex ocupada pelo aerênquima relatada no presente trabalho e em Pereira et al. (2008) e Souza et al. (2009).

Sabe-se que situações de deficit de oxigênio promovem estresse oxidativo, com acúmulo de EROs. De acordo com Blokhina et al. (2003), o acetaldeído normalmente acumulado sob essa condição pode funcionar como doador de elétrons e ativar $\mathrm{o}$ $\mathrm{O}_{2}{ }^{*}$ (íon superóxido) que, ao sofrer dismutação pela ação da dismutase do superóxido (SOD), forma $\mathrm{H}_{2} \mathrm{O}_{2}$,
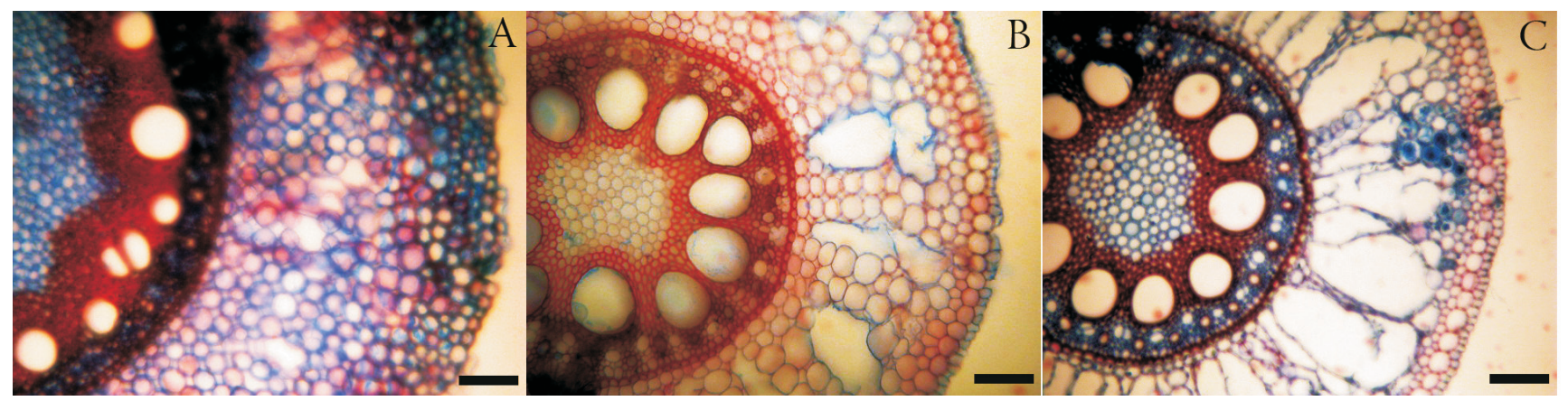

Figura 1. Desenvolvimento do aerênquima na variedade não tolerante ao alagamento BR 107 (A) e ao longo dos ciclos de seleção C1 (B) e C18 (C) do milho 'Saracura'. Barras $=200 \mu \mathrm{m}$. 
cujo conteúdo nas células é regulado pela ação da CAT e por diversas peroxidases, entre elas POD e APX. Por sua vez, o acúmulo de EROs em condições de alagamento (Kozlowski, 1984, 1997) pode estimular a produção de aerênquima, pela apoptose celular desencadeada pelo etileno (Schussler \& Longstreth, 1996; Drew, 1997).

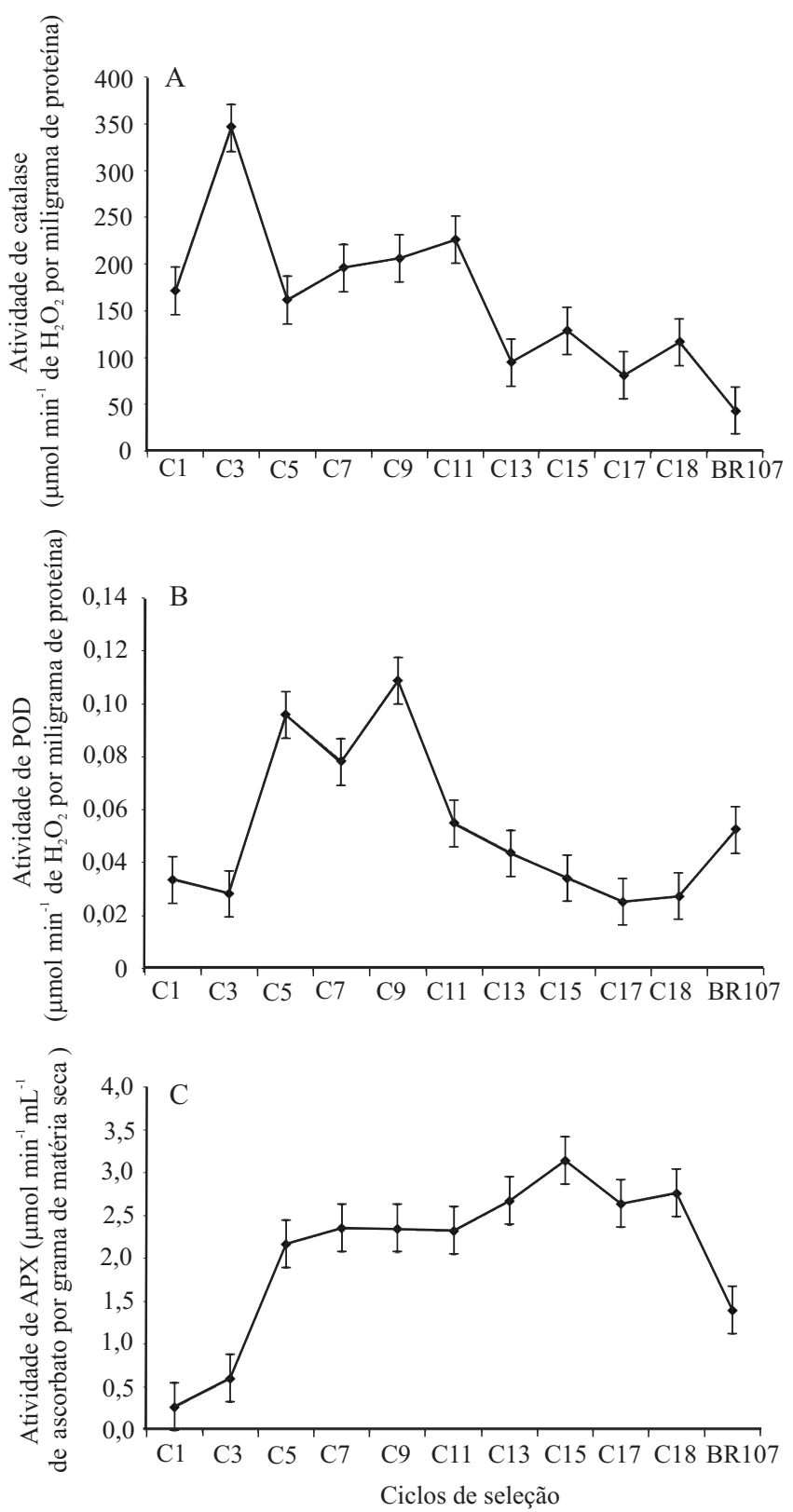

Figura 2. Atividade das enzimas catalase (A), peroxidase do guaiacol (POD, B) e peroxidase do ascorbato (APX, C) na raiz de plantas de diferentes ciclos de seleção do milho 'Saracura' submetidas a alagamento intermitente. As barras indicam o erro padrão da média.
A queda na atividade das enzimas CAT e POD observada entre os ciclos iniciais e finais de seleção (Figuras 2 e 3) pode levar a um acúmulo de $\mathrm{H}_{2} \mathrm{O}_{2}$. $\mathrm{O}$ acúmulo desse metabólito, decorrente da redução das atividades de CAT e POD, por sua vez, poderia resultar no estímulo na atividade da APX observado a partir do C3 (Figura 2) .

Como as atividades da CAT e POD também foram baixas no genótipo BR 107, o desenvolvimento de aerênquima não parece estar relacionado à atividade dessas enzimas, e deve requerer outros mecanismos celulares de viabilização do processo de apoptose. Dessa forma, o aumento na proporção de aerênquima no córtex radicular pode ter levado a uma menor produção de EROs, em razão da melhor difusão de $\mathrm{O}_{2}$ pela raiz, o que resultaria em menor produção de $\mathrm{H}_{2} \mathrm{O}_{2}$. Portanto, uma outra explicação para o comportamento contrastante da atividade enzimática de CAT e POD em relação a APX seria resultante da diminuição na produção de $\mathrm{H}_{2} \mathrm{O}_{2}$ nos ciclos finais de seleção. Essa redução pode ter levado às menores atividades de CAT e POD observadas nesses ciclos. Sendo a APX uma enzima considerada de maior eficiência para a decomposição do $\mathrm{H}_{2} \mathrm{O}_{2}$ (Madhusudhan et al., 2003), o aumento constatado em sua atividade pode ter sido decorrente da necessidade de se decompor o $\mathrm{H}_{2} \mathrm{O}_{2}$ formado, ainda que em menores proporções, nos ciclos finais de seleção.

Por outro lado, as isoenzimas aniônicas da POD estão relacionadas à formação de parede celular e síntese de lignina e suberina (Fieldes \& Gerhardt, 1998). Portanto, a queda na atividade dessa enzima pode ter levado à redução na síntese de parede celular, e tecidos lignificados nas raízes dos últimos ciclos. Desse modo, é aceitável que a redução na biossíntese de parede celular possa ser relacionada à maior formação de câmaras de aerênquima nas raízes dos últimos ciclos. Menor produção de tecidos suberizados nas raízes, como a camada de células suberizadas abaixo da epiderme e da endoderme, foram observados para os mesmos ciclos de seleção do milho 'Saracura' por Pereira et al. (2008), e em plantas dessa cultivar cultivadas no campo sob alagamento (Souza et al., 2009), o que reforça o possível papel das isoformas aniônicas da POD na formação de aerênquima. 


\section{Conclusões}

1. Maiores proporções de aerênquima no córtex radicular podem ser obtidas por seleção massal.

2. As enzimas catalase e peroxidase do guaiacol apresentam menor atividade nos ciclos finais de seleção do milho 'Saracura', enquanto a peroxidase do ascorbato apresenta comportamento contrário.

\section{Agradecimentos}

À Coordenação de Aperfeiçoamento de Pessoal de Nível Superior, ao Conselho Nacional de Desenvolvimento Científico e Tecnológico e à Embrapa Milho e Sorgo, pelo auxílio financeiro.

\section{Referências}

ALVES, J.D.; MAGALHÃES, M.M.; GOULART, P. de F.P.; DANTAS, B.F.; GOUVÊA, J.A. de; PURCINO, R.P.; MAGALHÃES, P.C.; FRIES, D.D.; LIVRAMENTO, D.E. do; MEYER, L.E.; SEIFFERT, M.; SILVEIRA, T. Mecanismos de tolerância da variedade de milho "Saracura" (BRS 4154) ao alagamento. Revista Brasileira de Milho e Sorgo, v.1, p.41-52, 2002.

ANDRADE, A.C.S. de; RAMOS, F.N.; SOUZA, A.F. de; LOUREIRO, M.B.; BASTOS, R. Flooding effects in seedlings of Cytharexyllum myrianthum Cham. and Genipa americana L.: responses of two neotropical lowland tree species. Revista Brasileira de Botânica, v.22, p.281-285,1999.

BLOKHINA, O.; VIROLAINEN, E.; FAGERSTEDT, K.V. Antioxidants, oxidative damage and oxygen deprivation stress: a review. Annals of Botany, v.91, p.179-194, 2003.

BOR, M.; ÖZDEMIR, F.; TÜRKAN, I. The effect of salt stress on lipid peroxidation and antioxidants in leaves of sugar beet Beta vulgaris L. and wild beet Beta maritima L. Plant Science, v.164, p.77-84, 2003.

BOURANIS, D.L.; CHORIANOPOULOU, S.N.; KOLLIAS C.; MANIOU, P.; PROTONOTARIOS, V.E.; SIYIANNIS, V.F.; HAWKESFORD, M.J. Dynamics of aerenchyma distribution in the cortex of sulfate-deprived adventitious roots of maize. Annals of Botany, v.97, p.695-704, 2006.

CAKMAK, I.; HORST, W.J. Effect of aluminum on lipid peroxidation, superoxide dismutase, catalase, and peroxidase activities in root tips of soybean (Glycine max). Physiologia Plantarum, v.83, p.463-468, 1991.

DREW, M.C. Oxigen deficiency and root metabolism: injury and acclimation under hypoxia and anoxia. Annual Review of Plant Physiology and Plant Molecular Biology, v.48, p.223-250, 1997.

FERRER, J.L.R.; MAGALHÃES, P.C.; ALVES, J.D.; VASCONCELOS, C.A.; DELÚ FILHO, N.; FRIES, D.D.; MAGALHÃES, M.M.; PURCINO, A.A.C. Calcium partially relieves the deleterius effects of hypoxia on a maize cultivar selected for waterlogging tolerance. Revista Brasileira de Milho e Sorgo, v.4, p.381-389, 2005.

FIELDES, M.A.; GERHARDT, K.E. Flax guaiacol peroxidases can be used to illustrate the possibility of misinterpreting the effects of stress on the activity of developmentally regulated enzymes. Plant Science, v.132, p.89-99, 1998.

GRISI, F.A.; ALVES, J.D.; CASTRO, E.M. de; OLIVEIRA, C.; BIOAGIOTTI, G.; MELO, L.A. de. Avaliações anatômicas foliares em mudas de café 'Catuaí' e 'Siriema' submetidas ao estresse hídrico. Ciência e Agrotecnologia, v.32, p.1730-1736, 2008.

GUNAWARDENA, A.H.L.A.N. Programmed cell death and tissue remodelling in plants. Journal of Experimental Botany, v.59, p.445-451, 2008 .

INSAUSTI, P.; GRIMOLDI, A.A.; CHANETON, E.J.; VASELLATI, V. Flooding induces a suite of adaptive plastic responses in the grass Paspalum dilatatum. New Phytologist, v.152, p.291-299, 2001.

JOHANSEN, D.A. Plant microtechinique. $2^{\text {nd }}$ ed. New York: Mc Graw-Hill, 1940. 300p.

KOZLOWSKI, T.T. Plant responses to flooding of soil. BioScience, v.34, p.162-167, 1984.

KOZLOWSKI, T.T. Responses of woody plants to flooding and salinity. Tree Physiology Monograph, n.1, p.1-29, 1997.

KRAUS, J.E.; ARDUIM, M. Manual básico de métodos em morfologia vegetal. Rio de Janeiro: Edur, 1997. 221p.

KRISHNAMURTHY, K.V.; KRISHNARAJ, R.; CHOZHAVENDAN, R.; CHRISTOPHER, F.S. The programme of cell in death plants and animals - a comparison. Current Science, v.79, p.1169-1181, 2000.

MADHUSUDHAN, R.; ISHIKAWA, T.; SAWA, Y.; SHIGEOKA S.; SHIBATA, H. Characterization of an ascorbate peroxidase in plastids of tobacco BY-2 cells. Physiologia Plantarum, v.117, p.550-557, 2003.

MELO, H.C. de; CASTRO, E.M. de; SOARES, A.M.; MELO, L.A. de; ALVES, J.D. Alterações anatômicas e fisiológicas em Setaria anceps Stapf ex Massey e Paspalum paniculatum L. sob condições de déficit hídrico. Hoehnea, v.34, p.145-153, 2007.

MITTLER, R.; VANDERAUWERA, S.; GOLLERY, M.; VAN BREUSEGEM, F. Reactive oxygen gene network of plants. Trends in Plant Science, v.9, p.490-498, 2004.

MOLLER, I.M.; JENSEN, P.E.; HANSSON, A. Oxidative modifications to cellular components in plants. Annual Review of Plant Biology, v.58, p.459-481, 2007.

MÜHLENBOCK, P.; PLASZCZYCA, M.; PLASZCZYCA, M.; MELLEROWICKZ, E.; KARPINSKI, S. Lysigenous aerenchyma formation in Arabidopsis is controlled by LESION SIMULATING DESEASE 1. The Plant Cell, v.19, p.3819-3830, 2007.

NAKANO, Y.; ASSADA, K. Hidrogen peroxide is scavenged by ascorbate specific peroxidase in spinach chloroplasts. Plant and Cell Physiology, v.22, p.867-880, 1981.

PEREIRA, F.J.; CASTRO, E.M. de; SOUZA, T.C. de; MAGALHÃES, P.C. Evolução da anatomia radicular do milho 
'Saracura' em ciclos de seleção sucessivos. Pesquisa Agropecuária Brasileira, v.43, p.1649-1656, 2008.

SAIRAM, R.K.; KUMUTHA, D.; EZHILMATHI, K.; DESHMUKH, P.S.; SRIVASTAVA, G.C. Physiology and biochemistry of waterlogging tolerance in plants. Biologia Plantarum, v.52, p.401-412, 2008.

SCHUSSLER, E.E.; LONGSTRETH, D.J. Aerenchyma develops by cell lysis in roots and cell separation in leaf petioles in Sagittaria lancifolia (Alimastaceae). American Journal of Botany, v.83, p.1266-1273, 1996.

SOUZA, T.C. de; CASTRO, E.M. de;PEREIRA, F.J.;PARENTONI, S.N.; MAGALHÃES, P.C. Morpho-anatomical characterization of root in recurrent selection cycles for flood tolerance of maize (Zea mays L.). Plant Soil and Environment, v.55, p.504-510, 2009.
SOUZA, T.C. de; MAGALHÃES, P.C.; PEREIRA, F.J.; CASTRO, E.M. de; SILVA JÚNIOR, J.M. da; PARENTONI, S.N. Leaf plasticity in successive selection cycles of 'Saracura' maize in response to periodic soil flooding. Pesquisa Agropecuária Brasileira, v.45, p.16-24, 2010.

UNIVERSITY OF TEXAS HEALTH SCIENCE CENTER. UTHSCSA ImageTool. Version 3.0. 2002. Disponível em: <http:// www.etaj.com.br/ bertei/imagenst/ImageTool/Home/download. htm>. Acesso em: 17 jun. 2010.

YAN,B.;DA, Q.;LIU, X.;HUANG, S.;WANG,Z.Flooding-induced membrane damage, lipid oxidation and activated oxygen generation in corn leaves. Plant and Soil, v.179, p.261-268, 1996.

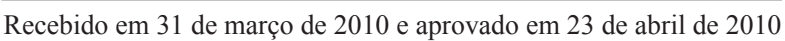

